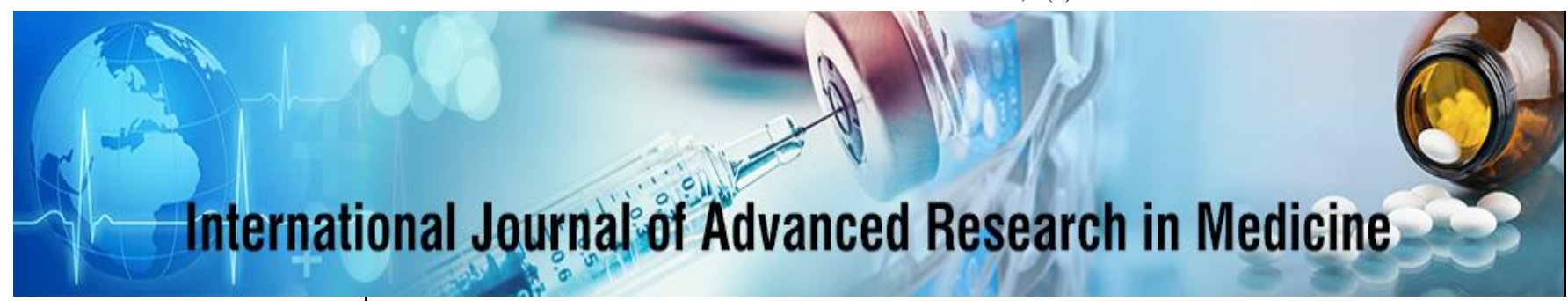

E-ISSN: 2706-9575

P-ISSN: 2706-9567

IJARM 2021; 3(1): 515-522

Received: 07-01-2021

Accepted: 09-03-2021

Dr. Yadvendra Singh

Junior Resident, Department

of Respiratory Medicine,

SRMS IMS, Bareilly,

Uttar Pradesh, India

Dr. Lalit Singh

Professor and Head,

Department of Respiratory

Medicine, SRMS IMS,

Bareilly, Uttar Pradesh, India

Dr. Rajeev Tandon

Associate Professor,

Department of Respiratory

Medicine, SRMS IMS,

Bareilly, Uttar Pradesh, India

Dr. Pradeep Nirala

Assistant Professor,

Department of Respiratory

Medicine, SRMS IMS,

Bareilly, Uttar Pradesh, India

Corresponding Author: Dr. Yadvendra Singh Junior Resident, Department of Respiratory Medicine, SRMS IMS, Bareilly,

Uttar Pradesh, India

\section{Extra-pulmonary tuberculosis (EPTB): Study of clinico-demographic profile, and comparison of microbiological diagnostic modalities with special emphasis on role of CBNAAT in detecting rifampicin resistance in fluid specimens}

\author{
Dr. Yadvendra Singh, Dr. Lalit Singh, Dr. Rajeev Tandon and \\ Dr. Pradeep Nirala
}

DOI: https://doi.org/10.22271/27069567.2021.v3.i1i.194

\begin{abstract}
The purpose of our study was to evaluate the place of CBNAAT in the diagnosis of extra-pulmonary TB in fluid specimens, and also detecting drug resistance in comparison to the Gold Standard - MGIT Bactec Culture.

Material and Methods: In prospective observational study of 2 yrs. among 165 EPTB cases, we studied the clinical presentation, compared the results of microbiological diagnostic modalities (ZN smear, CBNAAT, MGIT Culture) and evaluated the drug resistance.

Statistics: Used Chi square test via software STATA 15 and calculated p value.

Results: The positivity rate of CBNAAT $(31.30 \%)$ was higher than ZN smear $(23.92 \%)$, which was in turn higher than MGIT culture (9.9\%) and CBNAAT was able to detect Rifampicin resistance in $16.66 \%$ EPTB cases.

Conclusion: We concluded that, the role of CBNAAT in fluid specimens should not be undermined and should be preferred over the "Gold standard" MGIT culture.
\end{abstract}

Keywords: extra-pulmonary tuberculosis (EPTB), Cartridge based nucleic acid amplification test (CBNAT), Mycobacteria growth indicator tube (MGIT), Ziehl Neelsen (ZN) staining, rifampicin resistance

\section{Introduction}

As per evidence based INDEX TB guidelines, the committe laid "Conditional recommendations" for use of Cartridge-based nucleic acid amplification test (CBNAAT) in diagnosis of Lymph Node TB and CNS TB, and "Strong recommendation" against the use of CBNAAT in diagnosis of Pleural TB. This led us to re-evaluate the reasons behind such strong recommendations against its use especially in pleural TB cases, and review the older recommendations.

\section{Material and Methods}

After obtaining the approval from ethical committee and consent from participant subjects, we conducted a prospective observational study over a period of $2 \mathrm{yr}$. among 165 cases of clinically suspected extra-pulmonary TB cases above the age of 18 yrs. in our tertiary care centre. Among all these suspected EPTB cases we, initially studied the clinical presentation and demographic profile. Further we subjected all the fluid specimens to microbiological modalities (ZN Smear, CBNAAT, MGIT Bactec culture). We tabulated and compared the results of microbiological modalities and evaluated the Rifampicin resistance in these cases. Lastly we studied the correlation between microbiological diagnostic modalities and their radio-histopathological findings.

\section{Statistical analysis}

The data collected from 165 cases using proforma was tabulated and organized in Microsoft excel sheet. From this data master chart was prepared and tables were designed using 
different variables. The data from these tables was then analysed using Chi square test via software STATA 15 and $\mathrm{p}$ value was calculated for different groups and the difference among the groups was quoted as to be either significant or insignificant. Finally the different microbiological diagnostic modalities were compared with culture as gold standard and their correlation with radiohistopathological findings was studied.

\section{Observations and Results}

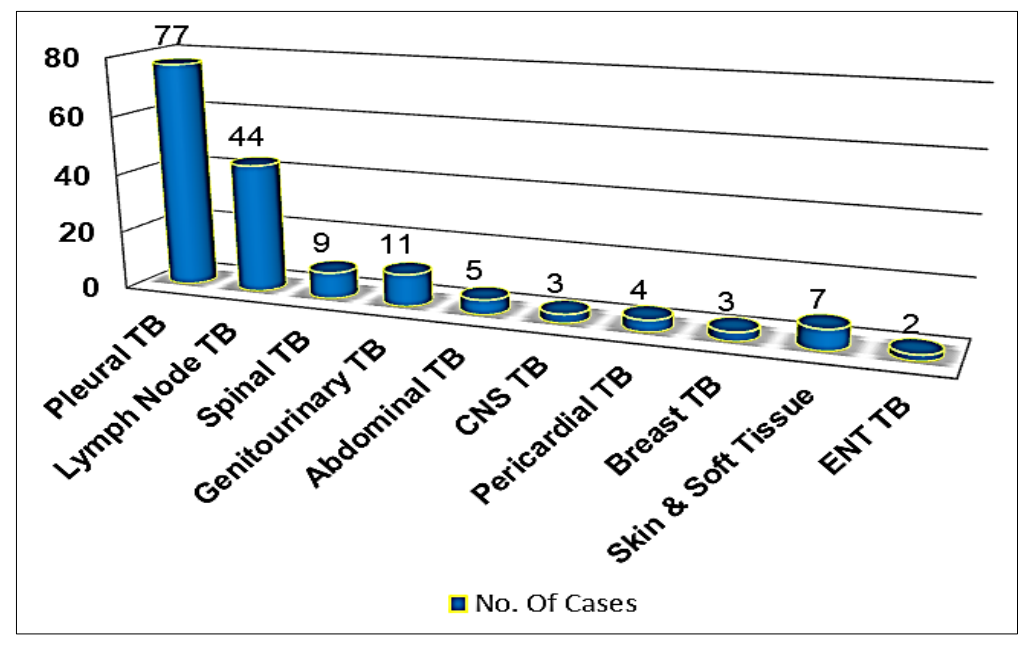

Fig 1: Presentation and distribution of different types of EPTB

Figure 1 shows presentation and distribution of 165 cases of EPTB in to 10 different groups based on system involved.

Table 1: Types of EPTB and age distribution

\begin{tabular}{|c|c|c|c|c|c|c|c|}
\hline $\begin{array}{c}\text { Age group } \\
\text { Type of EPTB }\end{array}$ & $\begin{array}{c}18-28 \mathrm{yr} . \\
{[\mathrm{n}=71](\%)}\end{array}$ & $\begin{array}{c}29-38 \text { yr. } \\
{[\mathrm{n}=31](\%)}\end{array}$ & $\begin{array}{c}39-48 \text { yr. } \\
{[\mathrm{n}=19](\%)}\end{array}$ & $\begin{array}{c}\text { 49-58 yr. } \\
(n=11)(\%)\end{array}$ & $\begin{array}{c}59-68 \text { yr. } \\
{[n=17](\%)}\end{array}$ & $\begin{array}{c}\text { 69-78 yr. } \\
{[\mathrm{n}=12](\%)}\end{array}$ & $\begin{array}{c}\text { 79-88 yr. } \\
{[\mathrm{n}=4](\%)}\end{array}$ \\
\hline Pleural TB $[\mathrm{n}=77]$ & $19(26.76)$ & $16(51.61)$ & $9(47.36)$ & $10(90.91)$ & $10(58.82)$ & $9(75)$ & $4(100)$ \\
\hline LN TB $[\mathrm{n}=44]$ & $27(38.03)$ & $7(22.58)$ & $5(26.32)$ & $1(9.09)$ & $4(23.53)$ & $0(0)$ & $0(0)$ \\
\hline Spine TB $[n=9]$ & $5(7.04)$ & $1(3.23)$ & $1(5.26)$ & $0(0)$ & $0(0)$ & $0(0)$ & $0(0)$ \\
\hline GU TB $[\mathrm{n}=11]$ & $9(12.68)$ & $1(3.23)$ & $1(5.26)$ & $0(0)$ & $0(0)$ & $0(0)$ & $0(0)$ \\
\hline Abdominal TB $[\mathrm{n}=5]$ & $4(5.63)$ & $0(0)$ & $0(0)$ & $0(0)$ & $1(5.88)$ & $0(0)$ & $0(0)$ \\
\hline CNS TB $[\mathrm{n}=3]$ & $0(0)$ & $1(3.23)$ & $1(5.26)$ & $0(0)$ & $0(0)$ & $1(8.33)$ & $0(0)$ \\
\hline Pericardial TB $[\mathrm{n}=4]$ & $1(1.41)$ & $2(6.45)$ & $0(0)$ & $0(0)$ & $1(5.88)$ & $0(0)$ & $0(0)$ \\
\hline Breast TB $[\mathrm{n}=3]$ & $2(2.82)$ & $1(3.23)$ & $0(0)$ & $0(0)$ & $0(0)$ & $0(0)$ & $0(0)$ \\
\hline SS TB $[\mathrm{n}=7]$ & $4(5.63)$ & $0(0)$ & $2(10.52)$ & $0(0)$ & $1(5.88)$ & $0(0)$ & $0(0)$ \\
\hline ENT TB $[n=2]$ & $0(0)$ & $2(6.45)$ & $0(0)$ & $0(0)$ & $0(0)$ & $0(0)$ & $0(0)$ \\
\hline $\begin{array}{c}\text { Total } \mathrm{n} / 165 \\
(\%)\end{array}$ & $\begin{array}{c}7171 / 165 \\
(43.03)\end{array}$ & $\begin{array}{c}3131 / 165 \\
(18.78)\end{array}$ & $\begin{array}{c}1919 / 165 \\
(11.51)\end{array}$ & $\begin{array}{c}1111 / 165 \\
(6.66)\end{array}$ & $\begin{array}{c}1717 / 165 \\
(10.30)\end{array}$ & $\begin{array}{c}1212 / 165 \\
(7.27)\end{array}$ & $\begin{array}{c}44 / 165 \\
(2.42)\end{array}$ \\
\hline
\end{tabular}

Pearson chi square $=64.14$, $\mathrm{p}$ value $=0.16$.

Table 1 shows the types of EPTB in different age categories.

Table 2: Types of EPTB on the basis of gender

\begin{tabular}{|c|c|c|c|}
\hline Type of EPTB & Male [n = 95] (\%) & Female [n= 70] (\%) & Total [N= 165] (\%) \\
\hline Pleural TB [n=77] & $60 / 95(63.15)$ & $17 / 70(24.28)$ & $77 / 165(46.66)$ \\
\hline LN TB [n=44] & $14 / 95(14.74)$ & $30 / 70(42.86)$ & $44 / 165(26.66)$ \\
\hline Spine TB [n=9] & $7 / 95(7.37)$ & $2 / 70(2.86)$ & $9 / 165(5.45)$ \\
\hline GU TB [n=11] & $2 / 95(2.11)$ & $9 / 70(12.86)$ & $11 / 165(6.66)$ \\
\hline Abdominal TB [n=5] & $3 / 95(3.16)$ & $2 / 70(2.86)$ & $5 / 165(3.03)$ \\
\hline CNS TB [n=3] & $2 / 95(2.11)$ & $1 / 70(1.43)$ & $3 / 165(1.82)$ \\
\hline Pericardial TB [n=4] & $2 / 95(2.11)$ & $2 / 70(2.86)$ & $4 / 165(2.42)$ \\
\hline Breast TB [n=3] & $0(0)$ & $3 / 70(4.29)$ & $3 / 165(1.82)$ \\
\hline SS TB [n=7] & $4 / 95(4.21)$ & $3 / 70(4.28)$ & $7 / 165(4.24)$ \\
\hline ENT TB [n=2] & $1 / 95(1.05)$ & $1 / 70(1.43)$ & $2 / 165(1.21)$ \\
\hline Total $n / 165$ & $9595 / 165$ & $7070 / 165$ & $165165 / 165$ \\
$(\%)$ & $(57.57 \%)$ & $(42.42 \%)$ & $(100 \%)$ \\
\hline
\end{tabular}

Pearson chi square $=37.16, \mathrm{p}$ value $<0.001$ (Statistically significant)

Table 2 shows types of EPTB with respect to gender. 


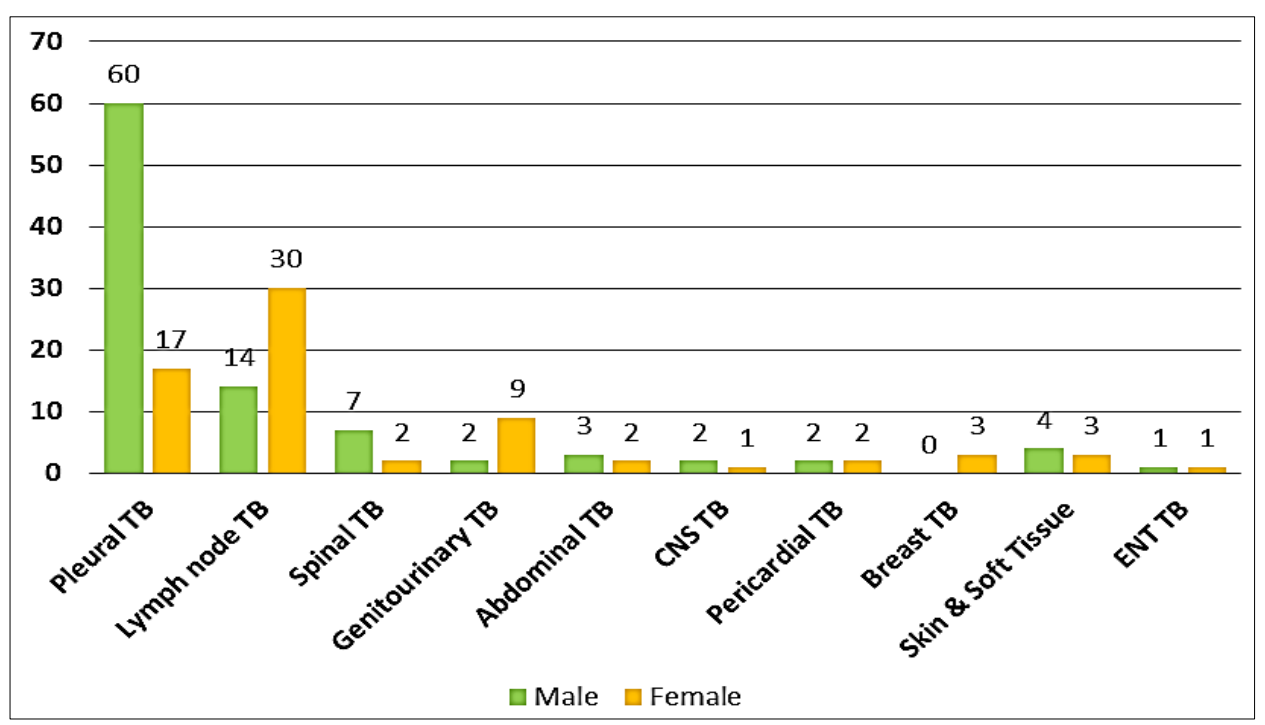

Fig 2: Distribution of different types of EPTB on basis of gender

Figure 2 shows that pleural $\mathrm{TB}(\mathrm{M}=60, \mathrm{~F}=17)$, spine $\mathrm{TB}$ $(\mathrm{M}=7, \mathrm{~F}=2)$, abdominal TB $(\mathrm{M}=3, \mathrm{~F}=2)$, CNS TB $(\mathrm{M}=$ $2, \mathrm{~F}=1)$, skin and soft tissue TB $(\mathrm{M}=4, \mathrm{~F}=3)$ were more common in male sex, whereas lymph node $\mathrm{TB}(\mathrm{M}=14, \mathrm{~F}=$
30), genitourinary $\mathrm{TB}(\mathrm{M}=2, \mathrm{~F}=9)$, breast $\mathrm{TB}(\mathrm{M}=0, \mathrm{~F}=$ $3)$, were more in female sex. However pericardial TB ( $\mathrm{M}=$ $2, \mathrm{~F}=2)$ and ENT TB $(\mathrm{M}=1, \mathrm{~F}=1)$ showed no sex predilection.

Table 3: Types of EPTB and area of residence

\begin{tabular}{|c|c|c|c|}
\hline Type of EPTB & Rural [n = 106] (\%) & Urban [n = 59] (\%) & Total [N = 165] (\%) \\
\hline Pleural TB [n=77] & $45 / 106(42.45 \%)$ & $32 / 59(54.24)$ & $77 / 165(46.66)$ \\
\hline LN TB [n=44] & $32 / 106(30.19)$ & $12 / 59(20.34)$ & $44 / 165(26.66)$ \\
\hline Spine TB [n=9] & $5 / 106(4.72)$ & $4 / 59(6.78)$ & $9 / 165(5.45)$ \\
\hline GU TB [n =11] & $8 / 106(7.55)$ & $3 / 59(5.08)$ & $11 / 165(6.66)$ \\
\hline Abdominal TB [n=5] & $2 / 106(1.89)$ & $3 / 59(5.08)$ & $5 / 165(3.03)$ \\
\hline CNS TB [n=3] & $2 / 106(1.89)$ & $1 / 59(1.69)$ & $4 / 165(1.82)$ \\
\hline Pericardial TB [n=4] & $4 / 106(3.77)$ & $0(0)$ & $3 / 165(2.42)$ \\
\hline Breast TB [n=3] & $1 / 106(0.94)$ & $2 / 59(3.39)$ & $7 / 165(4.82)$ \\
\hline SS TB [n=7] & $6 / 106(5.66 \%)$ & $1 / 59(1.69)$ & $2 / 165(1.21)$ \\
\hline ENT TB [n=2] & $1 / 106(0.94)$ & $1 / 59(1.69)$ & $165165 / 165$ \\
\end{tabular}

Pearson chi square $=7.51, \mathrm{p}$ value $=0.58$.

Table 3 shows the distribution of EPTB on the basis of area of residence.

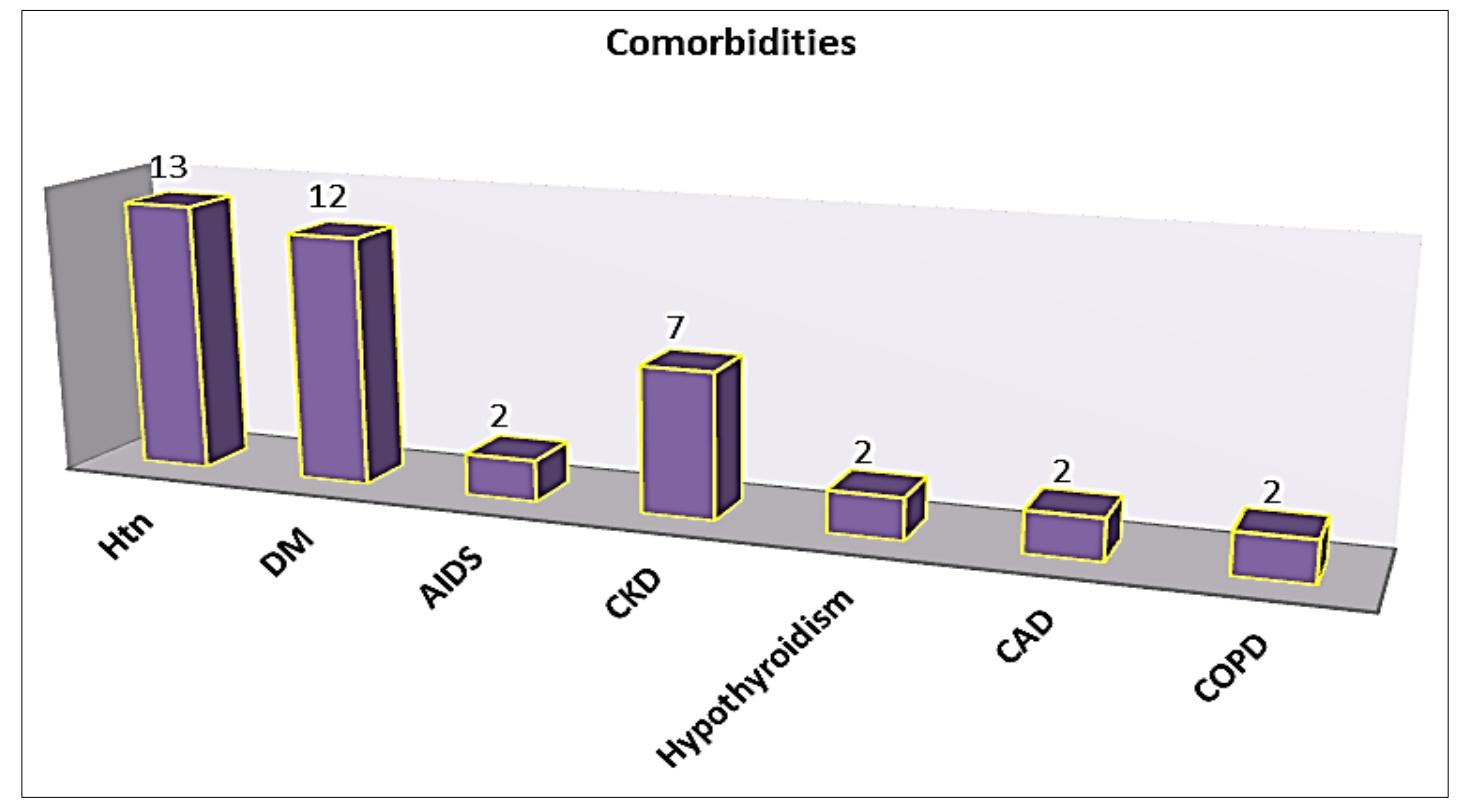

Fig 3: EPTB v/s Comorbidities 
Figure 3 shows that co-morbidities commonly associated with EPTB are HTN, DM, CKD.

Table 4: Type of EPTB v/s History of previously T/T PTB or EPTB

\begin{tabular}{|c|c|c|c|}
\hline Type of EPTB & Old T/t PTB [n = 3] (\%) & Old T/t EPTB [n = 18] (\%) & Total [N = 165] (\%) \\
\hline Pleural TB [n=77] & $3 / 77(3.89)$ & $1 / 77(1.29)$ & $77 / 165(46.66)$ \\
\hline LN TB [n = 44] & 0 & $9 / 44(20.45)$ & $44 / 165(26.66)$ \\
\hline Spine TB [n=9] & 0 & $2 / 9(22.22)$ & $9 / 165(5.45)$ \\
\hline GU TB [n =11] & 0 & $1 / 9(11.11)$ & $11 / 165(6.66)$ \\
\hline Abdominal TB [n=5] & 0 & 0 & $5 / 165(3.03)$ \\
\hline CNS TB [n=3] & 0 & 0 & $3 / 165(1.82)$ \\
\hline Pericardial TB [n 4] & 0 & 0 & $4 / 165(2.42)$ \\
\hline Breast TB [n=3] & 0 & $2 / 3(66.66)$ & $3 / 165(1.82)$ \\
\hline SS TB [n=7] & 0 & $3 / 7(42.85)$ & $7 / 165(4.24)$ \\
\hline ENT TB [n=2] & 0 & 0 & $2 / 165(1.21)$ \\
\hline Total $n / 165$ & $33 / 165$ & $1818 / 165$ & $165165 / 165$ \\
$(\%)$ & $(1.81 \%)$ & $(10.90 \%)$ & $(100 \%)$ \\
\hline
\end{tabular}

Table 4 shows that out of the 165 cases, 3 cases (1.81\%) had previous history of treatment for pulmonary tuberculosis and 18 cases $(10.90 \%)$ had previous history of treatment for extra-pulmonary tuberculosis.

Table 5: Type of EPTB and systemic symptoms

\begin{tabular}{|c|c|c|c|c|c|c|}
\hline \multirow{3}{*}{$\begin{array}{c}\text { Type of EPTB } \\
\text { Pleural TB } \\
{[\mathrm{n}=77]}\end{array}$} & \multicolumn{6}{|c|}{ Systemic symptoms } \\
\hline & Fever & Cough & Chest pain & Dyspnea & & \\
\hline & 49/77 (63.63) & $61 / 77(79.22)$ & 56/77 (72.72) & $36 / 77(46.75)$ & & \\
\hline \multirow[b]{2}{*}{$\begin{array}{l}\text { LN TB } \\
{[n=44]}\end{array}$} & Fever & Swelling & Single & Multiple & Tenderness & Sinus \\
\hline & $20 / 44(45.45)$ & $40 / 44(90.90)$ & $39 / 44$ (88.63) & $5 / 44(11.36)$ & $\begin{array}{c}15 / 44 \\
(34.09) \\
\end{array}$ & $\begin{array}{c}4 / 44 \\
(9.09) \\
\end{array}$ \\
\hline \multirow{2}{*}{$\begin{array}{l}\text { Spine TB } \\
{[\mathrm{n}=9]}\end{array}$} & Fever & Back pain & Deformity & Abscess & Neuro. Deficit & \\
\hline & $5 / 9(55.55)$ & $8 / 9(88.88)$ & $3 / 9(33.33)$ & $6 / 9(66.66)$ & $2 / 9(22.22)$ & \\
\hline \multirow{2}{*}{$\begin{array}{l}\text { GU TB } \\
{[n=11]}\end{array}$} & Fever & $\begin{array}{c}\text { Lower } \\
\text { Abd pain } \\
\end{array}$ & Urinary symptoms & $\begin{array}{l}\text { Menstrual } \\
\text { symptoms }\end{array}$ & Infertility & \\
\hline & $3 / 11(27.27)$ & $4 / 11(36.36)$ & $2 / 11(18.18)$ & $4 / 11(36.36)$ & $7 / 11(63.63)$ & \\
\hline \multirow{2}{*}{$\begin{array}{c}\text { Abdominal TB } \\
{[\mathrm{n}=5]}\end{array}$} & Fever & Abd. Pain & Distension & Vomiting & Diarrhea & Jaundice \\
\hline & $4 / 5(80.00)$ & $4 / 5(80.00)$ & $5 / 5(100.0)$ & $4 / 5(80.00)$ & $1 / 5(20.00)$ & $2 / 5(40.00)$ \\
\hline \multirow{2}{*}{$\begin{array}{c}\text { CNS TB } \\
{[n=3]}\end{array}$} & Fever & Headache & Vomiting & Alter. sensorium & Seizures & Neck rigidity \\
\hline & $2 / 3(66.66)$ & $2 / 3(66.66)$ & $1 / 3(33.33)$ & $3 / 3(100.0)$ & $1 / 3(33.33)$ & $2 / 3(66.66)$ \\
\hline \multirow{2}{*}{$\begin{array}{c}\text { Pericardial TB } \\
{[n=4]}\end{array}$} & Fever & Cough & Chest pain & Dyspnea & Orthopnea & \\
\hline & $3 / 4(75.00)$ & $3 / 4(75.00)$ & $3 / 4(75.00)$ & $3 / 4(75.00)$ & $3 / 4(75.00)$ & \\
\hline \multirow{2}{*}{$\begin{array}{c}\text { Breast TB } \\
{[\mathrm{n}=3]}\end{array}$} & Fever & Lump & Pain & Ulceration & Discharge & \\
\hline & $2 / 3(66.66)$ & $2 / 3(66.66)$ & $3 / 3(100.0)$ & $1 / 3(33.33)$ & $2 / 3(66.66)$ & \\
\hline \multirow{4}{*}{$\begin{array}{l}\text { SS TB } \\
{[n=7]}\end{array}$} & Fever & Plaque & Discoloration & Ulceration & Discharge & \\
\hline & $6 / 7(85.71)$ & $2 / 7(28.57)$ & $1 / 7(14.28)$ & $2 / 7(28.57)$ & $1 / 7(14.28)$ & \\
\hline & Cough & Chest pain & Dyspnea & & & \\
\hline & $5 / 7(71.42)$ & $5 / 7(71.42)$ & $5 / 7(71.42)$ & & & \\
\hline \multirow{2}{*}{$\begin{array}{c}\text { ENT TB } \\
{[n=2]}\end{array}$} & Fever & Sore Throat & Hoarseness & Swelling & Dysphagia & \\
\hline & $1 / 2(50.00)$ & $1 / 2(50.00)$ & $1 / 2(50.00)$ & $1 / 2(50.00)$ & $1 / 2(50.00)$ & \\
\hline
\end{tabular}

Table 5 shows the different systemic symptoms associated with different types of EPTB and their corresponding incidence

Table 6: Type of EPTB v/s AFB smear result

\begin{tabular}{|c|c|c|c|c|}
\hline Туре of ЕРТВ & $\begin{array}{c}\text { AFB smear } \\
+ \text { ve }[n=39](\%)\end{array}$ & $\begin{array}{c}\text { AFB Smear } \\
- \text { ve }[n=124](\%)\end{array}$ & $\begin{array}{c}\text { AFB smear not done } \\
{[n=2](\%)}\end{array}$ & $\begin{array}{l}\text { Total number } \\
{[N=165](\%)}\end{array}$ \\
\hline Pleural TB $[n=77]$ & $6 / 39(15.38)$ & $71 / 124(57.25)$ & 0 & $77 / 165(46.66)$ \\
\hline LN TB $[n=44]$ & $24 / 39(61.53)$ & $20 / 124(16.12)$ & 0 & $44 / 165(26.66)$ \\
\hline Spine TB $[n=9]$ & $1 / 39(2.56)$ & $8 / 124(6.45)$ & 0 & $9 / 165(5.45)$ \\
\hline GU TB $[\mathrm{n}=11]$ & $1 / 39(2.56)$ & $8 / 124(6.45)$ & $2 / 165(1.21)$ & $11 / 165(6.66)$ \\
\hline Abdominal TB $[\mathrm{n}=5]$ & $1 / 39(2.56)$ & $4 / 124(3.22)$ & 0 & $5 / 165(3.03)$ \\
\hline CNS TB $[n=3]$ & 0 & $3 / 124(2.41)$ & 0 & $3 / 165(1.82)$ \\
\hline Pericardial TB $[n=4]$ & 0 & $4 / 124(3.22)$ & 0 & $4 / 165(2.42)$ \\
\hline Breast TB $[\mathrm{n}=3]$ & $2 / 39(5.12)$ & $1 / 124(0.80)$ & 0 & $3 / 165(1.82)$ \\
\hline SS TB $[n=7]$ & $2 / 39(5.12)$ & $5 / 124(4.03)$ & 0 & $7 / 165(4.24)$ \\
\hline ENT TB $[n=2]$ & $2 / 39(5.12)$ & 0 & 0 & $2 / 165(1.21)$ \\
\hline $\begin{array}{c}\text { Total } \mathrm{n} / 165 \\
(\%)\end{array}$ & $\begin{array}{l}3939 / 163 \\
(23.92 \%)\end{array}$ & $\begin{array}{c}124 \\
124 / 163(76.07 \%) \\
\end{array}$ & $\begin{array}{l}22 / 165 \\
(1.21 \%)\end{array}$ & $\begin{array}{c}165165 / 165 \\
(100 \%)\end{array}$ \\
\hline
\end{tabular}

Pearson chi square $=74.32, \mathrm{p}$ value $<0.001$ 
Table 6 shows that out of 166 cases subjected to ZN smear examination, (39/163) $23.92 \%$ patients tested positive for AFB smear test. Among the smear positive cases, Maximum number of patients were found in the Lymph node TB
(24/39) $61.53 \%$ and pleural TB (6/39) $15.38 \%$. Statistically significant difference was found in between the groups. ( $p$ value $<0.001)$.

Table 7: Type of EPTB v/s Xpert MTB (CBNAAT/GENEXPERT) result

\begin{tabular}{|c|c|c|c|c|}
\hline Type of ЕРТВ & $\begin{array}{c}\text { MTB detected } \\
{[\mathrm{n}=36](\%)}\end{array}$ & $\begin{array}{c}\text { MTB Not detected } \\
{[n=79](\%)}\end{array}$ & $\begin{array}{c}\text { MTB Not done } \\
{[\mathrm{n}=50](\%)}\end{array}$ & $\begin{array}{l}\text { Total number } \\
{[N=165](\%)}\end{array}$ \\
\hline Pleural TB $[\mathrm{n}=77]$ & $18 / 36(50.00)$ & $59 / 79(74.68)$ & 0 & $77 / 165(46.66)$ \\
\hline LN TB $[\mathrm{n}=44]$ & $9 / 36(25.00)$ & $2 / 79(2.53)$ & $33 / 50(66.00)$ & $44 / 165(26.66)$ \\
\hline Spine TB $[\mathrm{n}=9]$ & $3 / 36(8.33)$ & $4 / 79(5.06)$ & $2 / 50(4.00)$ & $9 / 165(5.45)$ \\
\hline GU TB $[n=11]$ & $2 / 36(5.55)$ & $3 / 79(3.79)$ & $6 / 50(12.00)$ & $11 / 165(6.66)$ \\
\hline Abdominal TB [n=5] & 0 & $3 / 79(3.79)$ & $2 / 50(4.00)$ & $5 / 165(3.03)$ \\
\hline CNS TB $[n=3]$ & 0 & $2 / 79(2.53)$ & $1 / 50(2.00)$ & $3 / 165(1.82)$ \\
\hline Pericardial TB $[\mathrm{n}=4]$ & 0 & $3 / 79(3.79)$ & $1 / 50(2.00)$ & $4 / 165(2.42)$ \\
\hline Breast TB $[\mathrm{n}=3]$ & $2 / 36(5.55)$ & 0 & $1 / 50(2.00)$ & $3 / 165(1.82)$ \\
\hline SS TB $[n=7]$ & $2 / 36(5.55)$ & $3 / 79(3.79)$ & $2 / 50(4.00)$ & $7 / 165(4.24)$ \\
\hline ENT TB $[n=2]$ & 0 & 0 & $2 / 50(4.00)$ & $2 / 165(1.21)$ \\
\hline $\begin{array}{c}\text { Total } \mathrm{n} / 165 \\
(\%)\end{array}$ & $\begin{array}{l}3636 / 115 \\
(31.30 \%)\end{array}$ & $\begin{array}{l}7979 / 115 \\
(68.69 \%)\end{array}$ & $\begin{array}{l}5050 / 165 \\
(30.30 \%)\end{array}$ & $\begin{array}{c}165165 / 165 \\
(100 \%)\end{array}$ \\
\hline
\end{tabular}

Pearson chi square $=105.73, \mathrm{p}$ value $<0.001$

Table 7 shows that on Xpert MTB testing, MTB was detected in $36 / 115(31.30 \%)$ cases, and not detected in $79 / 115(68.69 \%)$ cases. Out of the 36 cases diagnosed to be MTB detected, $83.33 \%$ (30/36) cases were sensitive to rifampicin and $16.66 \%(6 / 36)$ cases were resistant to rifampicin. Maximum number of patients in whom MTB was detected belonged to Pleural TB (18/36) 50.00\%. P value was found to be statistically significant ( $\mathrm{p}$ value $<0.001)$.

Table 8: Type of EPTB v/s MGIT culture result

\begin{tabular}{|c|c|c|c|c|}
\hline Type of ЕРТВ & $\begin{array}{c}\text { Culture growth seen } \\
{[\mathrm{n}=11](\%)}\end{array}$ & $\begin{array}{c}\text { Culture no growth } \\
{[n=100](\%)}\end{array}$ & $\begin{array}{c}\text { Culture not done } \\
{[n=54](\%)}\end{array}$ & $\begin{array}{l}\text { Total number } \\
{[N=165](\%)}\end{array}$ \\
\hline Pleural TB [n = 77] & $9 / 11(81.82)$ & $68 / 100(68.00)$ & 0 & $77 / 165(46.66)$ \\
\hline LN TB $[\mathrm{n}=44]$ & $2 / 11(18.18)$ & $9 / 100(9.00)$ & $33 / 54(61.11)$ & $44 / 165(26.66)$ \\
\hline Spine TB $[n=9]$ & 0 & $7 / 100(7.00)$ & $2 / 54(3.70)$ & $9 / 165(5.45)$ \\
\hline GU TB $[\mathrm{n}=11]$ & 0 & $2 / 100(2.00)$ & $9 / 54(16.66)$ & $11 / 165(6.66)$ \\
\hline Abdominal TB [n $=5]$ & 0 & $2 / 100(2.00)$ & $3 / 54(5.55)$ & $5 / 165(3.03)$ \\
\hline CNS TB $[n=3]$ & 0 & $2 / 100(2.00)$ & $1 / 54(1.85)$ & $3 / 165(1.82)$ \\
\hline Pericardial TB $[\mathrm{n}=4]$ & 0 & $3 / 100(3.00)$ & $1 / 54(1.85)$ & $4 / 165(2.42)$ \\
\hline Breast TB $[\mathrm{n}=3]$ & 0 & $2 / 100(2.00)$ & $1 / 54(1.85)$ & $3 / 165(1.82)$ \\
\hline SS TB $[\mathrm{n}=7]$ & 0 & $5 / 100(5.00)$ & $2 / 54(3.70)$ & $7 / 165(4.24)$ \\
\hline ENT TB [n = 2] & 0 & 0 & $2 / 54(3.70)$ & $2 / 165(1.21)$ \\
\hline $\begin{array}{c}\text { Total } \mathrm{n} / 165 \\
(\%)\end{array}$ & $\begin{array}{c}1111 / 111 \\
(9.90 \%)\end{array}$ & $\begin{array}{c}100100 / 111 \\
(90.09 \%)\end{array}$ & $\begin{array}{l}5454 / 165 \\
(32.72 \%) \\
\end{array}$ & $\begin{array}{c}165165 / 165 \\
(100 \%)\end{array}$ \\
\hline
\end{tabular}

Pearson chi square $=100.47 P<0.001$

Table 8 shows that on MGIT culture, out of 111 cases, only 11 cases, (11/111) $9.90 \%$ cases were seen to have growth, whereas in (100/111) 90.09\% cases, no growth was seen. Of the 11 cases with Culture growth, Pleural TB cases constituted (9/11) $81.82 \%$ and Lymph node TB constituted (2/11) $18.18 \%$. The difference between the groups was found to be statistically significant.

Table 9: Comparison of microbiological diagnostic modalities

\begin{tabular}{|c|c|c|c|}
\hline & Smear + VE (n) & CBNAAT + VE (n) & MGIT growth (n) \\
\hline Pleural TB [n=77] & 6 & 18 & 9 \\
\hline LN TB [n $=44]$ & 24 & 9 & 2 \\
\hline Spine TB [n = 9] & 1 & 3 & 0 \\
\hline GU TB [n =11] & 1 & 2 & 0 \\
\hline Abdominal TB [n =5] & 1 & 0 & 0 \\
\hline CNS TB [n =3] & 0 & 0 & 0 \\
\hline Pericardial TB [n 4] & 0 & 0 & 0 \\
\hline Breast TB [n=3] & 2 & 2 & 0 \\
\hline SS TB [n=2] & 2 & 2 & 0 \\
\hline ENT TB [n=2] & 2 & 0 & $1111 / 111$ \\
\hline Total $n / 165$ & $3939 / 163$ & $3636 / 115$ & 9.90 \\
\hline
\end{tabular}


Table 9 depicts different types of EPTB, and shows comparison of various microbiological diagnostic modalities with culture as gold standard.

\section{Discussion}

Presentation and distribution of different types of EPTB: The distribution of different types of EPTB was Pleural TB (77/165) 46.66\%, Lymph node TB (44/165) 26.66\%, Genitourinary TB (11/165) 6.66\%, Spine TB (9/165) 5.45\%, Skin and Soft Tissue TB (7/165) 4.24\%, Abdominal TB (5/165) $3.03 \%$, Pericardial TB (4/165) $2.42 \%$, CNS TB (3/165) $1.81 \%$, Breast TB (3/165) $1.81 \%$, and ENT TB (2/165) $1.21 \%$. As per this distribution, most common type of EPTB was Pleural TB followed by Lymph node TB, whereas least common type of EPTB was ENT TB. These Findings were similar to that of the study conducted by Gaur PS et al. ${ }^{[1]}$ with 252 EPTB cases, which showed that the most common type of EPTB was pleural TB 138/252 (54.76\%), followed by lymph node TB 88/252 (34.92\%). Similarly in a study conducted by Velingker A et al. ${ }^{[2]}$ with 492 EPTB cases, the most common type of EPTB was pleural TB 194/492 (39.43\%), followed by lymph node TB 136/492 (27.64\%).

Types of EPTB and age distribution: Maximum number of EPTB patients (71/165) $43.03 \%$ belonged to age group of 18-28 yrs., whereas minimum number of patients (4/165) $2.42 \%$ belonged to age group of $79-88$ yrs. The results showed statistically insignificant $\mathrm{p}$ value. These Findings were similar to that of the study conducted by Gaur PS et al. ${ }^{[1]}$ in 252 EPTB cases, where the majority of cases $(105 / 252$, $41.7 \%$ ) belonged to $31-40 \mathrm{yr}$. age group and least number of cases $(26 / 252,10.3 \%)$. Similar results were found in study conducted by Shrivastava AK et al. ${ }^{[3]}$ among 130 EPTB patients, where the age group of 20-39 years had the highest proportion $(54 / 130,41.53 \%)$ of EPTB cases, while lowest proportion $(7 / 130,5.38 \%)$ was observed in the geriatric age group $>60$ years. Further in study conducted by Aravind et al. ${ }^{[4]}$ in 151 cases, the majority of cases $55 / 151(36.42 \%)$ belonged to age group of 21 to 30 years and the mean age of the sample was 38.9 years with a SD of 16.5 years.

Types of EPTB on the basis of gender: In our study EPTB cases were more common in male sex $(57.57 \%)$ compared to female sex $(42.42 \%)$. On comparing different types of EPTB on the basis of gender, the results showed statistically significant difference, ( $\mathrm{p}$ value $<0.001$ ). These Findings were similar to that of the study conducted by Shrivastava AK et al. ${ }^{[3]}$ where they found that out of 130 EPTB patients, $53.84 \%$ were males, $46.15 \%$ were females, with Male to female ratio of 1.16:1. Similarly in study conducted by Aravind et al. ${ }^{[4]}$ among 151 cases showed a male sex predominance with $78.7 \%$ males and $21.3 \%$ females. Also in study conducted by Tiwari VK et al. ${ }^{[5]}$ among 108 EPTB cases, 62 cases $(57.4 \%)$ were males and 46 cases $(42.5 \%)$ were females, which concluded male preponderance.

Types of EPTB and area of residence: Majority of the patient belonged to rural area (64.24\%) compared to urban area $(35.76 \%)$. However, No statistically significant difference was found in between the groups. This was similar to that of the study conducted by Shrivastava AK et al. ${ }^{[3]}$ where $62.30 \%$ patients were belong to urban areas and only $37.69 \%$ belong to rural areas. Also in study conducted by Pang Y et al. ${ }^{[6]}$ they found that most of the EPTB patients belonged to rural areas.

EPTB and associated co-morbidities: In our study most common comorbidity among EPTB patients was Hypertension (13/165) 7.87\%, followed by Diabetes mellitus (12/165) 7.27\%, and Chronic kidney disease (7/165) $4.24 \%$. However these findings were not in accordance with that of the study conducted by Gaur PS et al. ${ }^{[1]}$ among 252 EPTB cases, where DM was present in $16.7 \%$ cases. Similarly in the study conducted by Shrivastava AK et al. ${ }^{[3]}$ in 130 EPTB patients, they found that $7.69 \%$ had DM and was most commonly associated.

Type of EPTB v/s History of previously treated PTB or EPTB: In our study out of the 165 cases, 3 cases $(1.81 \%)$ had previous history of treatment for pulmonary tuberculosis and 18 cases $(10.90 \%)$ had previous history of treatment for extra-pulmonary tuberculosis. This finding was not in accordance with the results of study conducted by Aravind et al. ${ }^{[4]}$ which showed that $17.22 \%$ of the sample population had past history of pulmonary tuberculosis and this was significantly higher compared to our study.

Type of EPTB and systemic symptoms: In our study pleural TB findings were similar to that of the study conducted by Cohen LA et al. ${ }^{[7]}$ which stated that the most frequent symptoms in pleural TB are non-productive cough $(70 \%)$, which is usually non-productive, and pleuritic chest pain $(70 \%)$. Lymph node TB findings were similar to that of the study conducted by Gandhare A et al. ${ }^{[8]}$ which stated that the most common presentation in lymph node TB was single, non-tender lymphadenopathy, and fever was seen in $20-50 \%$, whereas sinus formation was relatively rare. Spinal TB findings were similar to that of the study conducted by Garg RK et al. ${ }^{[9]}$ which stated that back pain was the most common presenting feature. Genitourinary TB findings were similar to that of the study by Hemal AK et al. ${ }^{[10]}$ which stated that the association of tuberculosis and pelvic disease most frequently presented as infertility, lower abdominal pain, and altered menstrual pattern. Abdominal TB findings were similar to that of the study conducted by Underwood MJ et al. ${ }^{[1]}$ in 24 abdominal TB cases in which the most common presenting complaint was abdominal pain in $(21 / 24) 88 \%$, followed by weight loss in $(18 / 24) 75 \%$, anorexia in (15/21) 62\%, and night sweats in (13/24) $54 \%$. CNS TB findings were similar to that quoted by PN Sutlas et al. ${ }^{[12]}$ which stated that adults with tuberculous meningitis (TBM) present with the classic symptoms of fever, headache, neck stiffness and altered sensorium. Pericardial TB findings were in accordance with that of the study conducted by BM Mayosi et al. ${ }^{[13]}$ which stated that chest pain, cough, and dyspnea were the common presenting features. Skin and Soft tissue TB findings were in accordance with the observations of Wang SH et al. ${ }^{[14]}$ which stated that SS TB had a varied presentation. ENT TB findings were in accordance with that conducted by Michael RC et al. ${ }^{[15]}$ which stated that ENT TB typically presents with hoarseness, odynophagia, and dysphagia along with loss of weight and loss of appetite. Overall fever (95/165) $57.57 \%$ was the most common constitutional symptom 
associated with EPTB and night sweat (27/165) $16.36 \%$ was the least common.

Type of EPTB and ZN smear staining: In our study, out of 165 cases, 163 cases were subjected to $\mathrm{ZN}$ staining and in 2 cases it could not be done. Of the 163 cases, Smear for AFB was positive in $23.92 \%(39 / 163)$ and negative in $75.07 \%$ (124/163) cases. In the study conducted by Siddiqui MAM et al. ${ }^{[16]}$ with 100 EPTB specimens, subjected to ZN staining, ZN smear positivity was found to be $5 \%$. Also in study conducted by Bagdia et al. ${ }^{[19]}$ where 108 EPTB specimens were subjected to $\mathrm{ZN}$ smear examination, $\mathrm{ZN}$ smear positivity was found to be $9.28 \%$, both of these studies had ZN smear positivity lower than that of our study. Type of EPTB and Xpert MTB/RIF assay or PCR: Of the 165 cases of EPTB, Total of 115 cases were subjected to Xpert MTB (CBNAAT/Genexpert) and 50 cases were those in whom Xpert MTB could not be done. Of the 115 cases, MTB was detected in (36/115) $31.30 \%$ cases and MTB was not detected in (79/115) $68.69 \%$ cases. Thus Positivity rate of Xpert MTB/RIF assay was $31.30 \%$, which was higher than the positivity rate of $\mathrm{ZN}$ smear i.e., 23.92\%. These findings were in accordance with the study conducted by Munir MK et al. ${ }^{[17]}$ in 403 EPTB specimens to assess the value of GeneXpert in diagnosis in comparison with $\mathrm{ZN}$ smear microscopy and culture, where they found that the positivity rate of $\mathrm{ZN}$ smear was $67.5 \%$, of GeneXpert was $77.4 \%$ and of culture $85.1 \%$. Similarly in the study conducted by Li Y et al. ${ }^{[18]}$ in 420 EPTB specimens to evaluate the performance of Xpert MTB/RIF assay, the positivity rate of the Xpert MTB/RIF assay was found to be $18.4 \%$ (76/414), which was higher than culture (16.4\%, 68/414) and AFB smear $(9.2 \%, 38 / 414)$. Another study supporting our findings was that conducted by Bagdia et al. [19] where out of the 58 EPTB specimens subjected to ZN Staining, Genexpert and MGIT Culture, the positivity of Gene Xpert was $15.38 \%$ (8/58), of culture $12.06 \%$ (7/58), and of ZN stain $5.17 \%$ (3/58). Further in our study out of the 36 cases diagnosed to be MTB detected, 83.33\% (30/36) cases were sensitive to rifampicin and $16.66 \%$ (6/36) cases were resistant to rifampicin. Maximum number of patients in whom MTB was detected belonged to Pleural TB (18/36) $50.00 \%$.

Type of EPTB and MGIT culture: Of the 165 cases of EPTB, Total of 111 cases were subjected to MGIT Culture and 54 cases were those in whom MGIT Culture could not be done. Of the 111 cases, culture growth was seen in $(11 / 111) 9.09 \%$ cases and growth was not seen in (100/111) $90.09 \%$ cases. The culture positivity in our study was $9.90 \%$, which was lower than that of $\mathrm{ZN}$ smear positivity $(23.92 \%)$. These findings were in contrast to the results of the study conducted by Siddiqui MAM et al. ${ }^{[16]}$ in 100 EPTB specimens to compare conventional diagnostic modalities, where they found that the positivity of PCR was $70 \%$, BACTEC culture $15 \%$ and ZN smear 5\%. Similarly in the study conducted by Munir MK et al. ${ }^{[17]}$ the culture positivity was $18.46 \%$, which was considerably higher in comparison to the $\mathrm{ZN}$ smear positivity of $3.85 \%$. Also in the study conducted by Bagdia et al. ${ }^{[19]}$ in 108 EPTB specimens, culture positivity was $20.61 \%$, which was higher than ZN smear positivity of $9.28 \%$. Further in our study, out of the 11 EPTB cases with culture growth, (9/11) $81.82 \%$ were constituted by pleural TB and (2/11) $18.18 \%$ were constituted by lymph node TB. The difference between the groups was found to be statistically significant. (Pearson chi square $=100.47, P<0.001$ ).

From our study we found that, the overall positivity rate of Xpert MTB/RIF was (36/115) $31.30 \%$, with maximum proportion in pleural TB $(61.54 \%)$ followed by lymph node TB $(20.51 \%)$, which was higher than the overall positivity rate of ZN smear was (39/163) $23.92 \%$ and MGIT Culture was $(11 / 111) 9.9 \%$.

\section{Conclusion}

1. For Microbiological confirmation in fluid specimens, The Role of CBNAAT should not be undermined and should be preferred over the "Gold Standard" MGIT Culture and labelled as the "Platinum" of 21 st Century.

2. Earlier detection of Rifampicin Sensitive cases with CBNAAT compared to the time taking Gold Standard helps in quicker diagnosis, Earlier Treatment initiation and prevents Loss to follow up and avoids treatment failure.

3. Earlier detection of Rifampicin resistant in newly diagnosed EPTB cases helps in earlier initiation of Drug Resistant TB Regimen, which in turn led to better treatment outcome and Quality of life.

\section{References}

1. Gaur PS, Suryakant, Bhaskar R, Singh S, Saxena P, Agnihotri S. Incidence and Clinical profiles of Pulmonary and Extra-pulmonary Tuberculosis patients in North Indian population: A hospital based Retrospective study. Int J Res Dev Pharm L Sci 2017;6(5):2773-78.

2. Velingker A, Lawande D, Dcosta L. Clinicoepidemiological profile of extra pulmonary tuberculosis in Western India. Int $\mathbf{J}$ Contemp Med Res 2018;5(2):B1-B4.

3. Shrivastava AK, Brahmachari S, Pathak P, Kumar Ratan, Sainia T, Patel U et al. Clinico-Epidemiological Profile of Extra-pulmonary Tuberculosis in Central India. Int J Med Res Rev 2015;3(2):223-230.

4. Vadlakonda A, Rajiv G, Kirti S. Clinical Profile of Patients With Extra-pulmonary Tuberculosis at a Tertiary Care Hospital, New Delhi, IJMSCI 2017;4(1).

5. Tiwari VK, Agarwal R, Bansal S, Saini RK, Kumar A, Khan J. Study of the Clinical Profile and Site Proclivity of Extra-pulmonary Tuberculosis at Tertiary Care Center of Rohilkhand Region, Bareilly. Int J Adv Integ Med Sci 2016;1(3):95-97.

6. Pang Y, An J, Shu W, Huo F, Chu N, Gao M et al. Epidemiology of Extra-pulmonary Tuberculosis among Inpatients, China, 2008-2017. Emerg Infect Dis 2019;25(3):457-464.

7. Cohen LA, Light RW. Tuberculous Pleural Effusion. Turk Thorac J 2015;16(1):1-9.

8. Gandhare A, Mahashur A. Tuberculosis of the lymph nodes: Many facets, many hues. Astrocyte 2017;4:80-6.

9. Garg RK, Somvanshi DS. Spinal tuberculosis: a review. The Journal of Spinal Cord Medicine 2011;34(5):440454.

10. Hemal AK, Gupta NP, Rajeev TP, Kumar R, Dar L, Seth P. Polymerase chain reaction in clinically suspected genitourinary tuberculosis: comparison with intravenous urography, bladder biopsy, and urine acid fast bacilli culture. Urology 2000;56(4):570-4. 
11. Underwood MJ, Thompson MM, Sayers RD, Hall AW. Presentation of abdominal tuberculosis to general surgeons. Br J Surg 1992;79(10):1077-9.

12. Sutlas PN, Unal A, Forta H, Senol S, Kirbaş D. Tuberculous meningitis in adults: review of 61 cases. Infection 2003;31(6):387-91.

13. Mayosi BM, Burgess LJ, Doubell AF. Tuberculous pericarditis. Circulation 2005;112(23):3608-16.

14. Wang SH, Pancholi P. Mycobacterial skin and soft tissue infection. Curr Infect Dis Rep 2014;16(11):438.

15. Michael RC, Michael JS. Tuberculosis in Otorhinolaryngology: Clinical Presentation and Diagnostic Challenges. International Journal of Otolaryngology 2011, 1-4.

16. Ravikumar P, Priyadarshini Bai G. A study of extrapulmonary tuberculosis and its outcome. Int J Adv Med 2017;4(1):209-213.

17. Siddiqui MAM, Anuradha PR, Nagamani K, Vishnu $\mathrm{PH}$. Comparison of conventional diagnostic modalities, BACTEC culture with polymerase chain reaction for diagnosis of extra-pulmonary tuberculosis. J Med Allied Sci 2013;3(2):53-58.

18. Munir MK, Shabbir I, Iqbal R, Khan SU. Comparison of Ziehl Neelsen Microscopy with GeneXpert for Detection of Mycobacterium Tuberculosis. IOSRJDMS 2015;14(11):56-60.

19. Li Y, Pang Y, Zhang T, Xian X, Wang X, Yang J et al. Rapid diagnosis of extra-pulmonary tuberculosis with Xpert Mycobacterium tuberculosis/rifampicin assay. J Med Microbiol 2017;66(7):910-914.

20. Chakravorty S, Sen MK, Tyagi JS. Diagnosis of extrapulmonary tuberculosis by smear, culture, and PCR using universal sample processing technology. J Clin Microbiol 2005;43(9):4357-62.

21. Bagdia M, Bijwe S, Hirani N, Joshi A, Chowdhary A, Agarwal M et al. Lab Diagnosis of Extra Pulmonary Tuberculosis: Comparison of Histopathology, Cytology, Zeihl Neelsen stain and Light Emission Diode Microscopy with Culture and Nucleic Acid Amplification Tests. Int J Cur Res Rev 2018;10(8):1519. 